\title{
Americanismo, O NOVO MARCO DE CiênCia, TECNOLOgia E INOVAÇÁo: SEQUESTRO DO FUNDO PÚBLICO PELO CAPITAL FINANCEIRO
}

\author{
Americanism, The new Framework of Science, \\ Technology and InNOvation: SEQUestrum of THE PUbliC \\ FUND BY FINANCIAL CAPITAL
}

\begin{abstract}
João dos Reis Silva Júnior
Doutor em História e Filosofia da Educação pela Pontifícia Universidade Católica de São Paulo. Professor Titular da Universidade Federal de São Carlos. São Carlos, SP - Brasil jr@ufscar.br

Fabíola Bouth Grello Kato

Doutora em Educação pela Universidade Federal de São Carlos (2013) Professora adjunta da Universidade Federal do Pará (UFPA) fabiola_kato@hotmail.com

José Augusto Ewerton Mestre em Educação pela Universidade Federal do Pará. jaesousa@yahoo.com.br
\end{abstract}

\begin{abstract}
Resumo: Este artigo propóe-se a realizar uma análise sobre o contexto da financeirização da ciência produzida no Brasil potencializada pelo novo Marco Legal de Ciência, Tecnologia e Inovação (Lei no 13.243/2016). Com a ambiciosa expectativa da desburocratizaçáo das atividades de inovaçáo e pesquisa no país, as novas regras legais promovem a aproximação das instituiçóes e centros científicos no intento de impulsionar o investimento em pesquisa. Entretanto, com a ciência globalizada e mercantilizada, o fundo público nacional é sequestrado a fim de manter a hegemonia do capital financeiro. Para tanto, nossas análises se concentram no entendimento das leis regulatórias referentes à CT\&I e na reflexão sobre a mercantilização do conhecimento produzido para abastecer a economia mundial.
\end{abstract}

Palavras-chave: Financiamento da Pesquisa. Mercantilização da Ciência. Políticas Públicas.

AвSTRACT: This article proposes to carry out an analysis on the context of the financialization of science produced in Brazil enhanced by the new Legal Framework of Science, Technology and Innovation (Law $n^{\circ} 13.243 / 2016$ ). With the ambitious expectation of the de bureaucracy of innovation and research activities in the country, the new rules through law promote the approximation of scientific institutions and centers in an attempt to boost investment in research. However, with globalized and mercantilized science, the national public fund is hijacked in order to maintain the hegemony of financial capital. To this end, our analysis 
focuses on the understanding of the regulatory laws that affect CT\&I and the reflection on the mercantilization of the knowledge produced to supply the world economy.

Keywords: Research funding. Mercantilization of Science. Public Policy.

\section{Introdução}

Em cerimônia ocorrida em Brasília no dia 11 de janeiro de 2016, Dilma Rousseff (2011-2016) sancionou a Lei n. 13.243, que ficou conhecida como novo Marco Legal de Ciência, Tecnologia e Inovação. Recebida com aplausos pelos presidentes das principais associaçôes científicas do país, ministros, senadores, deputados, reitores, professores e pesquisadores, a aprovaçáo do novo marco legal, de acordo com o discurso proferido pela presidente da Sociedade Brasileira para o Progresso da Ciência (SBPC), Helena Nader, representava "o início de uma nova fase para a pesquisa e inovação tecnológica no Brasil” e cumpriria uma nova agenda para o setor ao integrar agentes públicos e privados que são parte do sistema de Ciência, Tecnologia e Inovação, dando segurança jurídica para a cooperação entre a comunidade científica, o governo e o setor empresarial. ${ }^{1}$

Por isso, hoje, sem dúvida, concordo com todos os que me antecederam, hoje é um dia marcante para o futuro do Brasil, porque hoje sancionamos o Marco Legal de Ciência, Tecnologia e Inovação. Estamos, com esse novo Marco Legal, promovendo uma reforma na legislação que regula a integração entre agentes públicos e agentes privados que integram nosso sistema de ciência, tecnologia e inovação. Estamos dando transparência, simplicidade e segurança jurídica a uma cooperação. Uma cooperação que é fundamental para o crescimento econômico, a geração de renda e emprego, e que promova ao mesmo tempo o desenvolvimento de forma sustentável ampliando oportunidades para nossa população. (ROUSSEF, 2016)

Em seu discurso, Dilma reconheceu tal marco regulatório como parte de um projeto de Estado que conduzirá o Brasil a um novo ciclo de 
desenvolvimento econômico e social, e que a aprovação dessa lei se traduz numa última etapa do que já se havia construído, em parte, com a aprovação da Emenda Constitucional 85/2015. Aponta indiretamente, em seu discurso, para um amplo projeto de reforma na política nacional de produção de conhecimento, que vem a conta gotas alterando as feiçóes da política nacional de ciência, tecnologia e inovação, com mudanças expressivas na forma de expansão do sistema e na regulação, tendo em vista a preparação do país para uma nova etapa de desenvolvimento produtivo pelo usufruto do fundo público pelo setor privado.

Nós vimos, nos últimos anos, aprimorando as legislaçóes e os instrumentos para estimular a cooperação entre governo, universidades, institutos de pesquisa, empresas para gerar inovação. Aprovadas em 2004 e em 2005, a Lei da Inovação e a chamada Lei do Bem, instituíram regras importantes para diminuir a distância entre a produção de ciência e a sua incorporação no processo produtivo. A expansão e a interiorização da rede federal de ensino técnico e de ensino superior buscaram promover a formação de técnicos, cientistas e profissionais qualificados em todo o nosso País, em todo o nosso território, o que era necessário ao atendimento das diferenciadas demandas do desenvolvimento regional. A criação da EMBRAP II e a expansão da rede de institutos tecnológicos e inovação do Senai foram parcerias vitoriosas entre o governo federal e a CNI. Foram iniciativas em favor da ampliação da oferta de novos equipamentos e laboratórios, como também do compartilhamento dos já existentes entre universidades e institutos públicos e o setor produtivo. (ROUSSEF, 2016)

O novo marco, portanto, foi apontado como um projeto que torna predominante a privatizaçáo da produção científica e tecnológica e figura entre um conjunto de medidas apresentadas pelo Senado da chamada Agenda Brasil, com o objetivo de retirar os direitos sociais e manter o superávit primário, favorecendo o uso dos recursos públicos pela iniciativa privada: 
Para Epitácio Macário, 2o vice-presidente do ANDES-SN e um dos coordenadores do Grupo de Trabalho de Ciência e Tecnologia (GTCT) do Sindicato Nacional, o PLC 77 representa uma regressão imensa no sistema público de ciência e tecnologia. 'O PLC é mais um ataque, um passo a mais na abertura das veias do fundo público para a apropriaçáo privada. Esse projeto abre a possibilidade de que as empresas privadas direcionem as pesquisas no país, faculta o compartilhamento de infraestrutura física e recursos humanos das universidades e institutos de pesquisa públicos com empresas privadas. $\mathrm{O}$ patrimônio humano e material de Ciência e Tecnologia públicos passarão a ser compartilhados, de acordo com a nova lei, com organizaçóes sociais e empresas privadas da área científica, explica. (ANDES, 2017)

Dentre os avanços do projeto de privatização contidos no novo Marco, o diretor do ANDES-SN destacava no âmbito do PLC 77/15 o fato da regulamentação e da criação e atuação das instituiçôes científicas, tecnológicas e de inovação (ICTs), que em sendo organizaçóes sociais ou empresas privadas, terão total acesso ao fundo público.

É um avanço vigoroso do processo de privatização dos recursos humanos e patrimônio científico públicos. Em médio prazo temos a possibilidade do conhecimento desenvolvido nas instituiçôes públicas não possam ser publicados pelos professores e pesquisadores, pois as ICTs vão deter a patente. Ou seja, a produção de conhecimento será patenteada e controlada por instituiçóes privadas, que funcionarão dentro das instituiçóes públicas. (ANDES, 2017) (SILVA JÚNIOR, 2017)

O novo Marco, portanto, de acordo com a fala da presidente da República à época, propunha mudanças significativas nas relaçóes de trabalho no interior das IFES ao dispor de expedientes que reestruturam o Plano de Carreiras e Cargos de Magistério Federal, que amplia o número de horas que os pesquisadores da rede pública em regime de dedicação ex- 
clusiva podem dedicar a atividades no setor privado, de 120 para 416 horas anuais, ou 8 horas semanais.

Isso vai possibilitar a justa remuneração das universidades públicas e dos centros de pesquisa, propiciando mais recursos para investimento e para novos avanços na qualidade da educaçấo e da produção de conhecimento. Permitirá, portanto, transformar a inovação bem-sucedida em patrimônio de toda a sociedade brasileira. Temos, portanto, muitos motivos para celebrar o novo Código Nacional de Ciência, Tecnologia e Inovação. Abrimos sem dúvida uma nova etapa na cooperação entre universidades, institutos de pesquisa, Estado e empresas, cujos resultados serão mais oportunidades para nossa população e mais competitividade para o nosso País. (ROUSSEF, 2016)

Tal marco regulatório para ciência, tecnologia e inovação, brevemente exposto, traduz-se na atualização de um projeto nacional que vem se institucionalizando, desde a década de 1990, num amplo processo de mercantilização da educação superior e da produção do conhecimento científico, caracterizado pela penetração de mecanismos e valores de mercado sobre a gestão, o financiamento, a avaliação e a produção de conhecimento em nossas universidades. Há, aqui, mais dois destaques: um primeiro consiste em que a instituição perde sua autonomia e o segundo não determina mais sua própria pauta de pesquisa. Há um deslocamento do lugar social antes e depois do novo Marco: sai de seu lugar histórico e passa a ocupar um espaço nas cadeias globais de valor, isto é, a universidade estatal brasileira ocupa um lugar na economia mundializada sob hegemonia do capital financeiro. Tudo isso pautado pelo discurso da democratização, da igualdade de oportunidades e da transformação social.

\section{Os antecedentes do novo Marco}

Como destacamos na sessão anterior, o novo marco legal de ciência, tecnologia e inovação é parte de uma política de Estado que já vem sendo formulada no Brasil desde meados dos anos 2000, operacionalizando-se 
por meio da formulação de uma agenda nacional a partir da gestão de Luís Inácio Lula da Silva. Destacamos os principais marcos políticos e jurídicos: a nova política de editais do CNPq (KATO, 2013), a Política Industrial, Tecnológica e de Comércio Exterior (PITCE, 2003), PAC CT\&I (20072010), a Política de Desenvolvimento Produtivo (PDP, 2008), a Lei de Inovação Tecnológica (2004), a Lei do Bem (2005) e a IV Conferência Nacional de CT\&I (2010). Vale destacar que a IV Conferência, que em última instância buscava tornar a Política de Ciência, Tecnologia e Inovação em política de Estado, cumpriu relevante papel histórico, produzindo a tríplice aliança entre a academia (representada pela SBPC e a Academia Brasileira de Ciência), o governo (como patrocinador do evento) e as principais autoridades governamentais ligadas à educação e à ciência, à tecnologia e à inovação e a economia mundializada, esta representada pela Confederaçáo Nacional da Indústria. Esse conjunto de medidas políticas e jurídicas passam a reorganizar o papel e a gestão da CT\&I do país, sobretudo com vistas a estimular a mudança da cultura de náo envolvimento do setor produtivo nas atividades de CT\&I.

É o governo de Lula (2003-2010) que vai dar solidez a este projeto, sobretudo, por meio de um novo projeto de industrialização que passa a reposicionar o setor produtivo/industrial ao atribuir a ele o papel de indutor de produção de conhecimento, tecnologia e inovação. Ou seja, a agenda nacional de C, T\&I, decorrente do novo projeto de industrialização brasileira, resultado da adaptação do país ao novo modelo econômico mundial, passando a demandar um novo ordenamento jurídico de orientação da produçâo de conhecimento científico, tecnológico e de incentivo à inovação. Sob esta perspectiva, o conhecimento passa a ser um dos elementos centrais da nova estrutura econômica brasileira, e a inovação tecnológica, a mediação entre a produção de conhecimento e a geração de riqueza. (KATO, 2013)

Tal agenda das políticas públicas de CT\&I no país, a partir dos anos 2000, já apontava para o necessário aumento da participação do setor produtivo nos investimentos em P\&D e isso alteraria as práticas institucionais 
do financiamento dessa atividade, passando a posicionar o setor produtivo como o grande indutor de ciência e tecnologia. Mais que isso, o setor produtivo passa a ser apenas o meio para inserção da ciência produzida no Brasil à economia mundial no âmbito das cadeias produtivas globais. O que torna as universidades estatais, únicas que produzem pesquisa, submissas às vicissitudes do capital financeiro. (SILVA JÚNIOR, 2017)

Outro grande desafio posto no centro do debate dessa agenda residia na importância de aumentar os gastos com CT\&I, buscando ampliar seus principais indicadores: a regionalização das atividades de pesquisa (muito clara hoje com a aprovaçáo do novo marco legal), aumento na produçáo de patentes e produção científica (sobretudo uma produção internacionalizada), ampliação da renúncia fiscal do governo para fomentar atividades e o dispêndio em P\&D nas empresas, criação de novos mecanismos de incentivo à mobilidade dos pesquisadores entre as universidades, centro de pesquisas e setor produtivo (a exemplo da Lei de Inovação Tecnológica e da criação dos fundos setoriais), projetos cooperativos que busquem a criação de ambientes favoráveis à inovação, capacitação de recursos humanos qualificados, em especial no campo das engenharias.

No âmbito da $4^{\circ}$ Conferência Nacional de Ciência, Tecnologia e Inovação, ocorrida no período de 26 a 28 de maio de 2010, o discurso do Ministro da Educação na ocasião, Fernando Haddad, antevia as principais medidas:

Nós temos hoje aqui nessa conferência muitos empresários inovadores, muitas entidades representativas do empresariado, e nós nunca tivemos uma conferência desse tipo, com uma discussão profunda envolvendo pessoas que tem atuado em setores diferentes, mas que perceberam a importância de nós juntarmos a academia, os centros de pesquisas com as empresas para que nós pensemos o grande desafio de fazer com que o conhecimento gere riqueza; o desenvolvimento sustentável e riqueza. $\mathrm{O}$ grande avanço então foi, exatamente, essa consolidação, e este plano de ciência e tecnologia é o resultado disso. Ele não partiu da cabeça de uma pessoa, de um ministério, mas ele foi, realmente, construído na sociedade. (HADDAD, 2010, grifo nosso) 
A fala do então presidente Lula durante a abertura da $4^{\circ}$ Conferência de CT\&I (2010) destacou que aquela conferência marcaria uma virada na produção de conhecimento por meio da nova política de CT\&I, transformando essa política pública em política de Estado. No terreno econômico, em primeiro lugar, a necessária relação entre política econômica e universidade, pois para que o país lograsse um posicionamento competitivo no mercado externo e passasse da condição de exportador de commodities para exportador de conhecimento, seria necessário um pacto entre academia, universidade e setor produtivo e uma ofensiva nos investimentos em ciência, tecnologia e inovação; em segundo lugar, de acordo com o então presidente, a incorporação do trinômio CT\&I como uma efetiva política de Estado, comprometida com o setor produtivo e o foco na inovação. Destaca-se, no plano da produção de conhecimento, que além de retirar a autonomia das universidades, pautar as pesquisas do país submetidas às cadeias globais de valor, impóe uma nova epistemologia ao pesquisador se o conhecimento se torna mercadoria no âmbito mundial e a pauta de pesquisa aí tem origem, a nova epistemologia tem em seu centro a racionalidade econômica.

[...] no Brasil, historicamente, nós fomos doutrinados a ser considerados seres inferiores. A gente no máximo disputava com a Bolívia, o Paraguai, com o Equador e quando chegava lá no Norte 'não vamos disputar com eles, pois eles são muito sabidos!'. Aí quando eu vejo um cientista dizer que nós já estamos no $13^{\circ}$, que nós já produzimos mais artigos que a Rússia, do que a Holanda. É motivo de orgulho para nós! [...] então a gente conseguiu mudar um pouco a história sendo teimoso [...] ser cientista nesse país era a arte de ser teimoso. Agora não, agora é a arte de fazer ciência num país que tem política de ciência, num país que tem políticas públicas. [...] para acabar com desafios desse país a prioridade é investimento em educação e ciência e tecnologia. Essa é a prioridade básica [...] tenho consciência que exportar um chipizinho deste tamanho que cabe numa caixa do tamanho dessa televisão vale mais que um navio de 300 toneladas de minério de ferro. Então nós queremos exportar inteligência, conhecimento e não ficar exportando commo- 
dities, que é importante, mas nós precisamos sofisticar. [o que se depreende daqui a mudança do tipo de conhecimento que se vai produzir, trata-se do "conhecimento-mercadoria" tradução livre do que desde 2010, Slaughter;Rhoades vem chamando de Raw Material Knowledge) (SILVA JÚNIOR, 2017)

Outro destaque na fala do presidente dizia respeito à indicaçáo de que, para colocar em movimento uma política de tal magnitude, seria necessário um novo pacto cultural na política de produção de conhecimento. Tal como exposto em sua fala, "o dinheiro disponibilizado para investimento em inovação nas empresas não foi. As pessoas não utilizaram, não apareceram empresários"; ou "Você precisa convencer os empresários a utilizar o dinheiro e fazer investimento em inovaçáo. [...] porque no Brasil, historicamente, nós fomos doutrinados a ser considerados seres inferiores." Tais excertos indicam que essa Conferência ratificou a necessidade jurídica de um consenso para pavimentar a construção de uma nova cultura acadêmico-institucional que aprimorasse a condução da política nacional de CT\&I. Aqui, há um problema estrutural. Florestan Fernandes mostrou que não houve uma revolução burguesa no Brasil, posto que a burguesia nacional se articulou com a internacional e de forma servil, fazendo com que os empresários brasileiros não tivessem um projeto de país, mas, ao contrário, se aproveitassem do fundo público nacional para a aliança nacional. ${ }^{2} \mathrm{O}$ que significa que todo esforço que foi feito não lograria sucesso.

No ano seguinte após a $4^{\circ}$ Conferência Nacional de Ciência, Tecnologia e Inovação, houve a apresentação, pelo Deputado Bruno Araújo (PSDB-PE), do Projeto de Lei 2.177/2011, com vistas a instituir o Código Nacional de Ciência, Tecnologia e Inovação:

A Lei no 13.243 , de 11 de janeiro de 2016, poderá ser responsável por uma das maiores reestruturaçôes do setor desde 2004, quando foi promulgada a Lei de Inovação (10.973/04). O novo marco, oriundo do Projeto de Lei (PL) no 2.177/11, foi proposto pelos Deputados Bruno Araújo, Antonio Imbassahy, Ariosto Holanda, Carlinhos Almeida, Izalci, José Rocha, Miro Teixeira, Paulo Piau, Rogério Peninha Mendonça e Sandro Alex, e tinha como objetivo inicial a instituição de um Código de Ciência, 
Tecnologia e Inovação. Para análise do projeto, foi constituída Comissão Especial e, em 2013, foi escolhido o Deputado Sibá Machado como relator da matéria.(BRASIL, 2016)

De acordo com o estudo técnico produzido pela consultoria legislativa da Câmara dos Deputados, publicado em 2016, o PL 2.177/11 tinha como ponto fulcral promover maior interação com o setor produtivo e produzir mudanças que trouxessem maior flexibilização à política de CT\&I do que as já produzidas no âmbito da Lei de Inovação Tecnológica. Acontece que, para produção de tal flexibilização era necessária uma alteração constitucional. A proposta esbarraria na Constituição Federal, que não previa, de maneira detalhada e expressa, a articulação entre entes públicos e privados e, principalmente, o financiamento e a transferência de recursos públicos a entidades privadas de pesquisa. De modo a introduzir essa nova visão no setor e pavimentar a posterior aprovação do PL, foi apresentada a Proposta de Emenda Constitucional (PEC) n. 290, de 2013, de autoria da Deputada Margarida Salomão.

A PEC foi aprovada e promulgada na forma da Emenda Constitucional (EC) no 85, de 26 de fevereiro de 2015. Entre as disposições, a EC instituiu a promoção da inovação pela articulação entre entes públicos e privados de ciência e tecnologia (Instituição Científica, Tecnológica e de Inovação - ICT) e criou um Sistema Nacional de Ciência, Tecnologia e Inovação para tal fim. A Emenda permitiu a destinação de verbas públicas para instituiçôes de fomento à pesquisa, assim como a contratação de bens e serviços por regimes simplificados. A alteração inclui a possibilidade de financiamento público a instituiçôes de pesquisa, tanto públicas quanto privadas, nas diversas esferas de governo, assim como permite que entidades não estabelecidas como empresas (caso da Fiocruz, por exemplo) e polos tecnológicos possam atuar em CTI. (BRASIL, 2016b, p. 6)

A Emenda Constitucional 85 de 2015 alterou e adicionou dispositivos na Constituição Federal para atualizar o tratamento das atividades de 
ciência, tecnologia e inovação, incluindo o conceito de inovação ao lado de ciência e tecnologia. Ao alterar os artigos 218 e 219, legaliza o incentivo à participação do Estado, pela via do fundo público, no estímulo de atividades no âmbito da ciência, tecnologia e inovação nas empresas. No $6^{\circ}$ parágrafo, escreve-se: "O Estado, na execução das atividades previstas no caput, estimulará a articulação entre entes, tanto públicos quanto privados, nas diversas esferas de governo." E ainda, no parágrafo único, o "Estado estimulará a formação e o fortalecimento da inovação nas empresas, bem como nos demais entes, públicos ou privados, a constituição e a manutenção de parques e polos tecnológicos e de demais ambientes promotores da inovação, a atuação dos inventores independentes e a criação, absorção, difusão e transferência de tecnologia."

No âmbito do Art. 219-B, estabelece o regime de colaboraçáo entre entes públicos e privados para o fortalecimento do Sistema Nacional de Ciência, Tecnologia e Inovação: "o SNCTI será organizado em regime de colaboração entre entes, tanto públicos quanto privados, com vistas a promover o desenvolvimento científico e tecnológico e a inovação". Após a atualização da Constituição Federal por meio da EC 85/15, o PL 2.177/11 recebeu novo impulso, sendo aprovada em janeiro de 2016.

Atualizada a Constituição e dado um novo propósito para o setor de CTI, o PL no 2.177/11 ganhou redobrado impulso e passou a tratar não mais da promulgação de um Novo Código, mas sim da regulamentação das novas diretrizes constitucionais. Nesse contexto, a Lei finalmente aprovada busca incentivar o desenvolvimento do setor por meio de três grandes eixos: i) a integração de empresas privadas ao sistema público de pesquisa; ii) a simplificação de processos administrativos, de pessoal e financeiro, nas instituiçóes públicas de pesquisa; e iii) a descentralização do fomento ao desenvolvimento de setores de CTI nos Estados e Municípios. (BRASIL, 2016b, p. 7)

Aos poucos a tese de Florestan Fernandes se atualiza. A construção do Novo Marco mostra a articulação da burguesia nacional, especialmente com os Estados Unidos. 


\section{A aprovação do Novo Marco Legal de Ciência Tecnologia e Inovaçáo}

A Lei mais atual, conhecida como Novo Marco Legal de Ciência, Tecnologia e Inovaçáo, Lei n. 13.243, aprovada em 11 de janeiro de 2016, dispóe sobre os incentivos ao desenvolvimento científico, à pesquisa, à capacitação científica e tecnológica e à inovação. Esse novo marco alterou 9 outras leis e recebeu elogios do governo e do empresariado. Há vários componentes de cunho empresarial de incentivo à comercialização dos resultados das pesquisas produzidas nas universidades dentro desse novo Marco: a missão das instituições de ensino superior públicas passa a ter a inovação tecnológica como fator central; permite a contratação de servidores (técnicos, pesquisadores, tecnólogos) sem exigência de concursos, em via de excepcionalidade (Art. 6), desregulamenta a dedicação exclusiva ao permitir e estimular que os docentes busquem remuneração adicional. Em seu Art. 14-A, dispóe: "O pesquisador público em regime de dedicação exclusiva, inclusive aquele enquadrado em plano de carreiras e cargos de magistério, poderá exercer atividades remuneradas de pesquisa, desenvolvimento e inovação em ICT ou em empresa e participar da execução de projeto aprovado ou custeado com recursos previstos nesta lei."

De acordo com o relatório técnico escrito pela comissão de assessoria jurídica da câmara legislativa, são três os principais objetivos mestres com a aprovação do novo marco: integração, desburocratização e simplificação.

1.Lei de Inovação (10.973/04) reescreveu a maior parte da lei para atender aos três novos eixos de integração, simplificação e descentralização. 2. Estatuto do Estrangeiro (6.815/80) incluiu possibilidade de emissão de visto temporário para pesquisador. 3. Lei de Licitaçốes (8.666/93) incluiu dispensa de licitação para aquisição de produtos para CTI, limitada, no caso de serviços, a R\$300.000,00. 4. Lei Regime Diferenciado de Contrataçôes Públicas - RDC (12.462/11) permitiu a adoção do RDC por entidades de CTI. 5. Lei da Contratação Temporária no Serviço Público (8.745/93) ampliou a possibilidade de contratação temporária em instituiçôes de CTI para incluir técnicos.6. Lei das Relaçóes Entre as Universidades (8.958/94) permitiu às funda- 
çôes de apoio ou aos Núcleos de Inovação Tecnológica de ICT o apoio a parques e polos tecnológicos, assim como o repasse de recursos diretamente a essas entidades. 7. Lei das Importaçóes de CTI (8.010/90) Alterou de "entidades sem fins lucrativos" para "ICT" o rol de agentes habilitados a importar com isenção de impostos. 8. Lei Importaçôes por Empresas (8.032/90) incluiu a possibilidade de isenção de impostos de importação para projetos de CTI realizados por empresas ou quando importados diretamente por pesquisadores. 9. Plano de Carreiras das Universidades (12.772/12) permitiu a professor, inclusive em dedicação exclusiva, ocupar cargo de direçáo em fundaçáo de apoio e ser, por isso, remunerado. Permitiu a percepção de bolsa paga por fundação de apoio, IFE (Instituiçôes Federais de Ensino) ou por organismo internacional, no regime de dedicação exclusiva. Passou de 120 horas para 416 horas anuais, ou 8 horas semanais, o limite para participação em atividades de CTI externas à ICT. (BRASIL, 2016b, p. 7-8)

As açóes acima destacadas se concretizam como parte da reforma universitária, ao colocar a produção de conhecimento na forma de fundo público tangível e intangível, patrimônio cultural de nossa sociedade, agora transvertido de inovação, a serviço do empresariado e da apropriação privada. A partir da constatação de que a estrutura de produçáo de conhecimento está de modo predominante nas universidades públicas, as metas para o próximo decênio seriam, portanto, a indução a uma maior sinergia entre o ensino de pós-graduaçáo, o setor empresarial e a sociedade.

No caso do modelo norte-americano, em pesquisa anterior (SILVA JUNIOR, 2017) se pode demonstrar que as alteraçóes na base produtiva do capitalismo provocaram o redesenho no financiamento público para as instituiçôes republicanas, alterando, gradativamente, o papel, o lugar e o financiamento da universidade estatal. Tal modelo de universidade inicia seu processo de consolidação com a aprovação, em 1980, do Bayh-Dole Act (1980), ou lei de patentes e licenciamentos, cujo objetivo central foi o incentivo à comercialização dos resultados das pesquisas nas universidades.

As alteraçóes trazidas, portanto, pelo Novo Marco Legal de Ciência, Tecnologia e Inovação, são provavelmente os principais meios de incentivo 
à inovação e tecnologia do Brasil criados recentemente de forma a atender a interesses econômicos de âmbito mundial. Para tanto, faz-se necessária a análise do conteúdo desse dispositivo.

A lei, no primeiro artigo, cumpre sua principal função, alterando grande parte da 10.973/2004, a Lei de Inovaçôes Tecnológicas. Iniciando pelo caput do art. $1^{\circ}$, é realizada uma alteração, com a menção de artigos da Constituição, que antes eram apenas o 218 e 219. Com a nova redação passaram a ser os artigos 23, 24, 167, 200, 213, 218, 219 e 219-A. Isso ocorreu porque esses artigos são os mesmos que foram alterados pela Emenda Constitucional no 85 e, na prática, a Lei no $13.243 / 16$ é uma regulamentação dos ditames dessa emenda.

\section{O detalhamento jurídico da expressão do Bayb-Dolle Act no Brasil}

A hegemonia dos Estados Unidos é total. Não há espaço para outro país. Algumas brechas, talvez, existentes no Reino Unido, na China e na França, mas que não interferem nos interesses estadunidenses, mantendose a realização da maioria de seus interesses. Até mesmo a Constituição brasileira de 1988, muito provavelmente a que mais foi influenciada pelo Estado de Bem-Estar Social, foi alterada com uma revisão constitucional sob a presidência de Fernando Henrique Cardoso, Lula da Silva e Dilma Roussef, para, no governo Temer, ser rasgada em apenas 18 meses. Para que os interesses na conformação da ciência brasileira fossem feitos segundo o neoamericanismo, produziu-se o Novo Marco; para torna-lo legal, emendas constitucionais, alterações em artigos e parágrafos da lei.

Neste sentido, entender as alterações constitucionais também é importante para uma análise do Novo Marco Legal. A emenda no 85 incluiu na Constituição a categoria 'inovação' como medida a ser garantida, no mesmo patamar de ciência e tecnologia. Além disso, destacou a necessidade de apoio financeiro público à tecnologia e inovaçáo no $\$ 2^{\circ}$ do art. 513. Mas, principalmente, estimula as parcerias entre o público e privado por meio das alteraçóes realizadas no artigo 218 e pela inclusão dos artigos 219-A e 219-B, os quais, inclusive, criam o Sistema Nacional de Ciência, Tecnologia e Inovação. Para regulamentar esse novo aparato jurídico cons- 
titucional, a Lei no 13.243/16 fez alteraçóes em outras legislações, resultando na inclusão, já no primeiro artigo da lei 10.973/2004, de um parágrafo único que dispóe sobre princípios para a promoção de CT\&I, dentre os quais se destacam:

I - Promoção das atividades científicas e tecnológicas como estratégicas para o desenvolvimento econômico e social; [...] IV - descentralizaçáo das atividades de ciência, tecnologia e inovação em cada esfera de governo, com desconcentração em cada ente federado; - promoção da cooperação e interação entre os entes públicos, entre os setores público e privado e entre empresas VI - estímulo à atividade de inovação nas Instituiçôes Científica, Tecnológica e de Inovação (ICTs) e nas empresas, inclusive para a atração, a constituição e a instalação de centros de pesquisa, desenvolvimento e inovação e de parques e polos tecnológicos no País; VII - promoção da competitividade empresarial nos mercados nacional e internacional; [...] XII - simplificação de procedimentos para gestáo de projetos de ciência, tecnologia e inovação e adoção de controle por resultados em sua avaliação. (BRASIL, 2004)

Esses acabam sendo os principais eixos do Novo Marco Legal de Ciência, Tecnologia e Inovação. Analisando mais profundamente as mudanças na lei de inovaçóes tecnológicas é preciso citar o art. $3^{\circ}$, que inclui a possibilidade de o Estado apoiar e cooperar com empresas estrangeiras por exclusão do termo empresas nacionais. Além disso, o apoio dos entes da federação a empresas, incluindo aí as estrangeiras, está expresso na redação do novo Art. $3^{\circ}-\mathrm{B}$, ademais da atração de empresas estrangeiras, expressamente estimulada na inclusão do Art. $3^{\circ}-\mathrm{C}$ :

A União, os Estados, o Distrito Federal e os Municípios estimularão a atração de centros de pesquisa e desenvolvimento de empresas estrangeiras, promovendo sua interação com ICTs e empresas brasileiras e oferecendo-lhes o acesso aos instrumentos de fomento, visando ao adensamento do processo de inovação no País. (BRASIL, 2016a) 
O apoio estatal e a utilização do fundo público para estimulo a iniciativa privada é bastante perceptível nas medidas do art. $4^{\circ}$, com a nova redação dos incisos I e II, que criam a possibilidade de uma ICT pública:

I - Compartilhar seus laboratórios, equipamentos, instrumentos, materiais e demais instalaçôes com ICT ou empresas em açóes voltadas à inovação tecnológica para consecução das atividades de incubação, sem prejuízo de sua atividade finalística; (BRASIL, 2016a)

Tal possibilidade era, até entáo, apenas possível às pequenas empresas. Segue-se, no inciso II, o objetivo de

Permitir a utilização de seus laboratórios, equipamentos, instrumentos, materiais e demais instalaçôes existentes em suas próprias dependências por ICT, empresas ou pessoas físicas voltadas a atividades de pesquisa, desenvolvimento e inovação, desde que tal permissão não interfira diretamente em sua atividade-fim nem com ela conflite; (BRASIL, 2016a)

Isso só era permitido às empresas brasileiras ou organizaçóes sem fins lucrativos; agora, estende-se a entidades e empresas nacionais e estrangeiras de direito privado, com ou sem fins lucrativos. $\mathrm{O}$ artigo $8^{\circ}, \$ 1^{\circ}$, traz uma importante novidade ao permitir que as ICTS públicas celebrem convênios sem que necessariamente seu representante legal máximo realize contrato, podendo esse delegar a outras autoridades.

$\mathrm{O}$ art, $9^{\circ}$ e seus parágrafos incluem a possibilidade de estudantes receberem bolsas diretamente da ICT, sem caracterizar vínculo empregatício, bem como a possibilidade de cessão total de propriedade intelectual ao parceiro privado (pode ser cedido ao parceiro privado mediante pagamento) e a possibilidade de venda desses direitos de criação a terceiros. Em sentido parecido, o Art. 11 prevê a cessão de direito ao criador mediante remuneração. $\mathrm{O}$ art.14-A garante que pesquisadores de ICTs públicas, mesmo que em regime de dedicação exclusiva, possam realizar pesquisas para 
a iniciativa privada de forma remunerada. Há a criação de contratação com dispensa de licitação para o fornecimento de produtos relacionados à atividade de pesquisa no Art. 20, $\$ 4^{\circ}$.

Além desses novos dispositivos supramencionados, considerados aqui mais significativos, outros cumprem o objetivo de descentralizar o estímulo à inovação e aproximar o público e o privado. Todavia, a Lei n. 13.243/16 também fez alteraçóes na Lei noํ․ 6.815/80, facilitando a estadia de pesquisadores estrangeiros no Brasil:

Art. 13. O visto temporário poderá ser concedido ao estrangeiro que pretenda vir ao Brasil: V - na condição de cientista, pesquisador, professor, técnico ou profissional de outra categoria, sob regime de contrato ou a serviço do governo brasileiro; (BRASIL, 2016a)

A legislação também produz mudanças na Lei de Licitaçóes (8.666/93), para facilitar aquisiçáo de produtos relacionados a pesquisa e desenvolvimento de CTI que não ultrapassem o valor de $\mathrm{R} \$ 300.000$ (trezentos mil reais) com a inclusão do inciso XXI no art. 24. E mesmo esse valor sendo ultrapassado criou-se uma facilidade para a realização de licitaçôes por meio de dispensa de documentos essenciais para habilitação no art. $32, \$ 77^{\circ}$. No art. $5^{\circ}$ do novo Marco foi realizada a inclusão na Lei $12.462 / 11$ do inciso X, art. $1^{\circ}$, para dessa forma instituir o Regime Diferenciado de Contratações Públicas (RDC), aplicável exclusivamente às licitações e contratos necessários à realização das ações em órgãos e entidades dedicados à ciência, à tecnologia e à inovação, o que facilita a contratação de empresas pelo serviço público. Os artigos $8^{\circ}$ e $9^{\circ}$ da Lei 13.243/16 destinam-se a criar facilidades a importaçóes relacionadas a CTI, por meio de isençóes de impostos.

A Lei $8.745 / 93$, em seu art. $2^{\circ}$, que trata da inclusão de técnico com formação em área tecnológica de nível intermediário, ou de tecnólogo, em instituição destinada à pesquisa, ao desenvolvimento e à inovação, facilitou a contratação de temporários. No artigo 10 é alterado o Plano de Carreiras e Cargos de Magistério Federal de modo a garantir que docentes possam exercer cargo de dirigente máximo em fundação de apoio e ainda 
garante a remuneração dos mesmos por meio da inclusão do art. 20-A. No regime de dedicação exclusiva ainda se incluiu o seguinte:

III - bolsa de ensino, pesquisa, extensão ou estímulo à inovação paga por agência oficial de fomento, por fundaçáo de apoio devidamente credenciada por IFE ou por organismo internacional amparado por ato, tratado ou convenção internacional; $\$ 4^{\circ}$ As atividades de que tratam os incisos XI e XII do caput não excederão, computadas isoladamente ou em conjunto, a 8 (oito) horas semanais ou a 416 (quatrocentas e dezesseis) horas anuais. (BRASIL, 1993)

Este último parágrafo é um aumento da carga horária possível de o professor realizar fora da ICT. Ressalte-se que benefícios parecidos sáo concedidos em sentido amplo a todos os servidores da Administração Pública, de acordo com o que dispóe o art. 14 do novo Marco Legal de Ciência e Tecnologia.

Como se pode notar, quando tal Marco se realizar nas universidades estatais, a mercantilizaçáo dessas instituiçôes se completa, a exemplo da nova universidade americana ou da universidade de classe mundial. ${ }^{3}$ Mais uma vez o Brasil segue como plataforma de realização de valor, especialmente para os grupos americanos com sede nos Estados Unidos.

\section{Conclusão}

A explicação para a estrutural mudança no sistema de produção do conhecimento no Brasil encontra-se com mediaçôes mais amplas e que alcancem as relações entre o regime de predominância financeira, os Estados Unidos e o Brasil. A existência do Novo Marco é exigência estrutural do capitalismo sob esse regime, em última instância. Se ficamos presos ao pé da letra da lei morreremos sem compreender o que de fato motiva toda essa mudança que o Novo Marco pôs em movimento. De forma breve, tentaremos desenhar o mosaico que se esconde no fenômeno do ordenamento jurídico detalhado anteriormente. 
A economia que se manifestou no pós segunda-guerra mundial produziu historicamente e demasiadamente demandas para a indústria, em especial às corporaçóes de âmbito mundial, dada a imprescindibilidade das exigências estruturais que requisitou a diminuição de tempo entre a produção científica e sua aplicação em serviços, produtos e processos. A ciência básica ou aplicada, destinada para o bem público, tem aí uma intimidação para a mudança, sendo basilar um novo tipo de conhecimento que obedeça a tais demandas, postas náo mais por indicadores exclusivamente científicos, mas também pela financeirização da economia. Esta se converte no principal fator para a epistemologia da nova ciência acadêmica, em face, especialmente, da posição econômica e bélica que os Estados Unidos passaram a ocupar em nível global.

As corporaçóes estrangeiras exigem que universidades realizem parcerias e criem redes de trabalho a fim de produzir conhecimento estratégico por meio de transferência de tecnologia, ou seja, realiza a venda de direitos autorais, fato que pode ser verificado na realidade das pesquisas feitas nas universidades estatais brasileiras. Esse conhecimento, na maioria das vezes, é transferido na forma de inovaçóes sociais e tecnológicas e é o tipo de conhecimento que aqui denomino 'conhecimento matéria-prima', termo que tem inspiração na leitura dos trabalhos de Gary Rhoades, Sheila Slaugther, Gustavo Fischman e Daniel Schugurensky. Para o abastecimento da economia mundial, o conhecimento matéria-prima torna-se parte dos resultados científicos em seu novo paradigma. O conhecimento pronto revela-se como um produto, convertido em alta tecnologia por meio dos novos processos de produçáo remetidos a lucros imediatos no campo econômico. (SCHUGURENSKY, D.; NAIDORF, J, 2004)

De maneira geral, podemos destacar que esse é um processo, ao mesmo tempo, de mudança, invenção e adaptação, que existe desde as primeiras sociedades na história da humanidade, tendo como objetivo o aperfeiçoamento da vida e do trabalho das pessoas e das empresas, agregando mais valor aos produtos no menor tempo possível. Ao analisar a realidade histórica, o maior problema do capital consistia em reduzir o gap entre a ciência e a tecnologia e, mesmo que houvesse a aproximação entre universidade e indústria, ocorria considerável demora na soluçáo dos problemas. Entretanto, com a quebra do monopólio de produçáo e a emergência da predominância financeira, esse cenário altera-se de forma radical. Dá-se 
que o ciclo de capital portador de juros faz dinheiro sem trabalho. Por meio da equação marxista, entende-se que D' > D, isto é, o proprietário do dinheiro investe, empresta e recebe os juros como forma de pagamento dessa operação pela propriedade privada do dinheiro. Este, além de ser um procedimento econômico, é também jurídico, porque impóe as taxas de juros e o tempo de pagamento do que é devido, desdenhando o que irá acontecer no processo de produção real de valor. É uma aposta com o menor risco e a maior rentabilidade.

Tal operação pode ser realizada por empresários, grupo de empresas, países, agentes institucionalizados que atuam no mercado, sendo guias da gestão do sistema monetário mundial, aos quais se subordinam os fundos de pensão e os fundos de hegemonia industrial, caracterizando um regime de predominância financeira. E como consequência disso, no âmbito jurídico, o ciclo financeiro comprime não só o ciclo do capital em funçôes (as relações sociais de produção), mas também as relaçôes sociais em geral, transformando a subjetividade e a sociabilidade do todo ser humanocidadão ao exigir a produção de valor real em tempo recorde, em vida, por meio do trabalho. Esse é o problema central do capital e a necessidade de fazer obliterar o gap entre ciência e tecnologia. A universidade e a pesquisa nela produzida, nesse ponto, cumprem um estratégico papel efetuando a redefinição da ciência e do conhecimento, e a lógica econômico-financeira se interpóe nas práticas quotidianas da vida universitária. Nesse caso, o que as pesquisas, o trabalho do pesquisador e do professor precisam apresentar é o conhecimento matéria-prima.

O interesse do capital financeiro é que novos conhecimentos provenientes dessa mesma natureza sejam indefinidamente produzidos. Isso está na fonte das explicaçóes das reformas universitárias, na financeirização da ciência, no financiamento das universidades, na sua gestão e organização, e na avaliação, dada a importância dos rankings pela necessidade de expansão e internacionalização da educação superior por meio da nova divisão internacional do trabalho científico, pelo acesso ao conhecimento que é produzido nessas instituiçóes. É relevante destacar o que os autores denunciam de maneira cientificamente consistente nos seus trabalhos - a necessidade da publicação, tornadas mercadorias destinadas às mãos de seis editoras no mundo todo, por meio da venda dos direitos autorais da produção de seus pesquisadores profissionais nas universidades. Esses 
pesquisadores recebem adicionais, além de seus respectivos salários, por venderem sua produção (conhecimento matéria-prima) por quantia razoável às universidades em que trabalham. No entanto, as publicaçóes que ocorrem em áreas do conhecimento como farmacêutica, tecnológicas e matemática tornam-se patentes quando uma equação ou uma solução química se converte em produto financeiro em Wall Street. Essas mudanças estruturais induzem o pesquisador a publicar em abundância e muitas vezes repetir o que já foi escrito por ele com a ajuda do ambicioso luxo da estética: as diversas formas de plágio e autoplágio. As tecnologias da informação reduzem o tempo de publicação e aumentam o tempo de exposiçáo do texto, rigorosamente administrada.

A compressão espaço-temporal própria da sociedade atual e exigida pela economia mundial sob o predomínio do capital financeiro exige a compressão do tempo epistêmico e neurológico do pesquisador, produzindo, nele, muito sofrimento. Essa situação aliena o ser humano trabalhador na universidade. Seu trabalho é fantasticamente voltado para a busca de resultados comercializáveis. A epifania de si ocorre de forma eficiente e gera o adoecimento do homem; a atmosfera de uma vida estranha póe sua existência em cheque, porque ele não entende se é a sua própria sombra, sua imagem no espelho, sua foto digitalizada no currículo Lattes, na página de um diretório de pesquisa ou no research gate. Suas dimensóes humanas se estilhaçam e o fazem voltar-se e revoltar-se contra si mesmo e se identificar com a necessidade de 'mais'.

\section{Notas}

1 A Lei institucionalizava processo que já se vinha desenvolvendo no Brasil desde a IV Conferência de Ciência, Tecnologia e Inovaçấo realizada em maio de 2010. Ainda que em sua forma inicial, não era único, tampouco uma iniciativa de países emergentes, posto que tal processo também se desenvolvia nas economias centrais e o Brasil buscava envolver-se com esses países na organização da 'tríplice hélice' de Etzkowitz (2008), empresa-universidade-governo, com sucesso. As inovaçóes ocupavam lugar central e por isso as universidades eram chamadas a participar de forma adaptativa; a empresa era considerada o centro do crescimento econômico. A diferença entre o Brasil e os países de economia central consistia na servidáo financeira de parte daquele (Cf. PAULANI, 2008), portanto, de transformar conhecimento matéria-prima em aumento da produtividade industrial e aumento da rentabilidade econômica do país.

2 Na terceira parte de seu livro Revoluçäo Burguesa no Brasil, segundo Ricardo Musse, Fernandes produz o conceito de 'capitalismo dependente', que passa a demarcar a associação da burguesia com o capital internacional. Com isso, altera-se o peso da dinâmica do sistema capitalista mundial e a própria periodizaçáo, marcada pela emergência e expansão de três tipos de capitalismo: o moderno 
(1808-1860), o competitivo (1860-1950) e o monopolista (1950-1970). Em seguida, com a crise do Estado Keynesiano, emergiu o Regime de Predominância Financeira. (Ver CHESNAIS, 1995). Disponível em:<https://blogdaboitempo.com.br/2014/03/28/a-revolucao-burguesa-no-brasil/>.

3 O conceito de World Class University é polissêmico e depende do país que buscará ter um sistema de educação superior bastante heterogêneo, tendo nas universidades de classe mundial a elite de suas instituiçóes nesse nível educacional. O Banco Mundial, em seu relatório The Challenge of Establishing World-Class Universities busca caracterizar e induzir os países para um tipo de universidade de pesquisa internacionalizada, que agregue valor à economia do país, seja financiada pelo fundo público e privado e avaliada por indicadores, com predominância da racionalidade econômica. (SILVA JÚNIOR; CARVALHO, 2017)

\section{Referencias}

ANDES-SN. Marco Legal de Ciência, Tecnologia e Inovação (Lei 13.243/16): riscos e consequências para as universidades e a produção científica no Brasil. Brasília:

ANDES-SN, março de 2017. Disponível em:< http://portal.andes.org.br/imprensa/ documentos/imp-doc-1508946885.pdf>. Acesso em: 30 abr. 2018.

BRASIL. Lei no 13.243. Dispóe sobre os estímulos ao desenvolvimento científico à pesquisa, à capacitação científica e tecnológica e à inovação. 11 de janeiro de 2016a. Disponível em:< http://www.planalto.gov.br/ccivil_03/_ato2015-2018/2016/lei/113243. htm>. Acesso em: 04 de jun, 2017.

Lei 10.973. Dispóe sobre os incentivos à inovação e à pesquisa científica e

. Lei 8.745. Dispóe sobre a contratação por tempo determinado para atender tecnológica no ambiente produtivo. 02 de dezembro de 2004. Disponível em: <http:// www.planalto.gov.br/ccivil_03/_ato2004-2006/2004/lei/110.973.htm>. Acesso em: 30 nov. 2012. a necessidade temporária de excepcional interesse público, nos termos do inciso IX do art. 37 da Constituição Federal, e dá outras providências. 09 de dezembro de 1993. Disponível em: <http:// http://www.planalto.gov.br/ccivil_03/LEIS/L8745cons.htm>. Acesso em: 11 dez. 2018.

\section{Emenda Constitucional n.85. Altera e adiciona dispositivos na Constituição} Federal para atualizar o tratamento das atividades de ciência, tecnologia e inovação. 26 de fevereiro de 2015. Disponível em:< http://www2.camara.leg.br/legin/fed/ emecon/2015/emendaconstitucional-85-26-fevereiro-2015-780176-publicacaooriginal146182-pl.html>. Acesso em: 15 mar. de 2018.

. Câmara dos Deputados. As mudanças promovidas pela lei $n^{\circ} 13.243$, de 11 de janeiro de 2016 (novo marco legal de ciência, tecnologia e inovação) e seus impactos no setor. Estudo Técnico, Brasília, junho de 2016b. Disponível em: <http://www2.camara. leg.br/a-camara/documentos-e-pesquisa/estudos-e-notas-tecnicas/areas-da-conle/ tema11/2016_7581_mudancas-promovidas-pela-lei-13-243-marco-legal-cti-claudionazareno>. Acesso em: 20 abr. 2018. 
BRASIL. Casa Civil. Diretrizes de Politica Industrial, Tecnológica e de Comércio Exterior. Brasília, DF, 2003.

BRASIL. Ministério da Ciência e Tecnologia (MCT). Ciência, Tecnologia e Inovação para o desenvolvimento nacional: plano de ação (2007-2010). Brasília, 2007.

CHESNAIS, François. A mundialização do capital. São Paulo: Xamã Editora, 1996.

ETZKOWITZ, Henry. A tripla hélice: inovação universidade-indústria-governo em ação. Routledge, 2008.

HADDAD, Fernando. Conferência de Abertura. In: IV Conferência Nacional de Ciência, Tecnologia e Inovação. Brasília, 23 de maio de 2010. Transcrição Livre.

KATO, Fabíola. A nova política de financiamento de pesquisas: reforma no Estado e no novo papel do CNPq. 2013.179 f. (Doutorado em Educação) -Universidade Federal de São Carlos, São Carlos, 2013.

PAULANI, Leda. Brasil delivery. São Paulo: Boitempo, 2008.

ROUSSEF, Dilma. Discurso da Presidenta da República, Dilma Rousseff. [durante a cerimônia de sanção do marco legal da ciência, tecnologia e inovação e lançamento da chamada universal] - Brasília/DF. Disponível em:<http://www2.planalto.gov.br/ acompanhe-o-planalto/discursos/discursos-da-presidenta/discurso-da-presidenta-darepublica-dilma-rousseff-durante-a-cerimonia-de-sancao-do-marco-legal-da-cienciatecnologia-e-inovacao-e-lancamento-da-chamada-universal-brasilia-df $>$. Acesso em: 18 mar. 2018.

SCHUGURENSKY, D.; NAIDORF, J. Parceria universidade-empresa e mudanças na cultura acadêmica: análise comparativa dos casos da Argentina e Canadá. Educação \& Sociedade, Campinas, SP, v. 25, n. 88, 2004. Especial. Universidade: reforma e/ou rendição ao mercado?

SILVA JÚNIOR, Joao dos Reis. The new Brazilian University a busca por resultados comercializáveis: para quem? Bauru, SP: Canal 6 Editora, 2017.

CARVALHO, C.; SILVA JÚNIOR, João dos Reis Pesquisa, pós-graduação e conhecimento mercadoria no Brasil. EccoS Revista Científica, São Paulo, núm. 44, , 2017, pp. 23-42.

Recebido em I2 ago. 2018 / Aprovado em I2 nov. 2018

Para referenciar este texto:

JÚNIOR, J. R. S.; KATO, F. B. G.; EWERTON, J. A. Americanismo, O novo marco de Ciência, Tecnologia e Inovação: sequestro do fundo público pelo capital financeiro. EccoS - Revista Científica, São Paulo, n. 47, p. 171-193. set./dez. 2018. Disponível em: <https:/doi.org/10.5585/EccoS.n47.10757>. 
